\title{
The Capability Approach: A Framework for Population Studies
}

\author{
Enrica Chiappero-Martinetti ' and Sridhar Venkatapuram ${ }^{2}$ \\ ${ }^{1}$ University of Pavia and Institute for Advanced Study, Pavia, Italy ${ }^{i}$ \\ ${ }^{2}$ King's College London, London, United Kingdom \\ enrica.chiappero@unipv.it
}

\begin{abstract}
The aim of this paper is to present the main elements of the Capability Approach (CA) and discuss how and to what extent it can be a useful framework for capturing and analyzing population issues. Since the initial idea of Sen in 1979 to introduce the notion of human "capabilities" as a coherent alternative to measuring poverty, an extensive interdisciplinary school of thought has developed an analytical and normative framework that is outlined here in the first section. After introducing the CA, we sketch out a step-by-step procedure to use the CA in empirical analysis, focusing on the linkages among the plurality of circumstances at the individual, household and contextual levels. The fourth section discusses the approach shared by the CA and the population paradigm as formulated at the Cairo conference, which shifted away from aggregate indicators and biological functionings to a focus on choice and capabilities.
\end{abstract}

Keywords: human capabilities, conversion factors, functionings, agency, Cairo consensus.

\section{Résumé}

L'objectif de cet article est de présenter l'approche des Capabilités (AC) et commenter comment et dans quelle mesure elle constitue un cadre utile pour capter et analyser les questions de population. Depuis l'idée initiale de Sen en 1979 d'introduire la notion de "capabilités" humaines comme alternative cohérente aux mesures économiques de la pauvreté, une importante école de pensée interdisciplinaire a développé un cadre analytique et normatif qui est décrit ici dans la première section. Après avoir présenté l'approche des Capabilités, nous proposons une procédure pour l'appliquer dans les analyses empiriques en mettant l'accent sur les liens entre les nombreuses circonstances qui modulen tles situations au niveau des individus, des ménages et du contexte. Dans la quatrième section, nous discutons des fondements communs entre l'AC et les questions de population telles que formulées à la Conférence du Caire et qui s'est distancié des objectifs quantitatifs pour mettre l'accent sur le choix et les capabilités.

Mots-cles: Capabilités humaines, facteurs de conversion, fonctionnement, agency, concensus du Caire.

\section{Introduction}

The initial idea for the theory of human capabilities can be traced back to the 1979 Tanner Lecture on Human Values entitled "Equality of what?" given by the Nobel Prize laureate Amartya Sen. In the lecture he identified the weaknesses of measuring inequality, poverty and well-being purely in terms of income or resources, negative liberties, basic needs, or utility (happiness) and suggested human "capabilities" and capabilities equality/equity as a more coherent alternative. Over the three decades since the lecture, and following from many publications by Sen on the subject, an extensive interdisciplinary school of 
thought has developed around the initial idea of human capabilities. Scholars, researchers, and practitioners have developed and used the approach as an analytical and normative framework in which to ground theoretical, evaluative, and prospective analyses as well as concrete applications in a broad range of fields. These have included the analysis and measurement of national wellbeing, poverty and inequality, the prescription and design of welfare policies, the modeling and evaluation of development projects, and the assessment of living standardsii.

The aim of this paper is to discuss how, and to what extent, the capability (or capabilities) approach can be a useful framework for capturing and analyzing demographic concepts and questions. The next section outlines Sen's theoretical framework and its main constitutive elements while in section 3 we sketch out a step-by-step procedure for how the capability approach can be used for empirical analysis. In Section 4 discusses the potential value added of this framework for demographic analysis. Section 5 concludes.

\section{A short overview of the Capability Approach}

The capability approach (CA) is a broad analytical and normative framework that redefines the concepts of human well-being and social development (Sen 1985, 1992, 1999, 2009). It describes and analyzes individual wellbeing or quality of life in terms of her practically possible opportunities to achieve various outcomes - "beings and doings" - that make up a good or flourishing life. From a CA perspective, social development or progress is the expansion of such real opportunities of people in a society. The CA places individuals, their values, their real opportunities to be and do some basic things in a good life, and their freedom of choice in the spotlight as well as envisions well-being as something that is intrinsically multidimensional.
In any analysis of human wellbeing, the CA perspective starts out by asking this fundamental question: "What are people actually able to be and to do in their daily lives?" It then goes on to examine the range of real opportunities (capabilities) that people have to choose among as well as effectively realize those opportunities into beings and doings ("functionings") that they value for their own lives. Accordingly, the CA posits that the ultimate aim of development or social progress - in developing and rich countriesshould be that of expanding people's real opportunities or freedoms to realize beings and doings that constitute a good or flourishing life. Thus, the analytical contribution is the measuring of wellbeing correctly in terms of capabilities in contrast to resource holdings, liberties, basic needs, or utility all of which have significant weaknesses. And the normative contribution is the philosophical justification for every individual's moral claim to capabilities and for a conception of a good society as one that protects and expands human capabilities.

Five constitutive elements characterize this framework iii. The first concept is of capability itself. It is the answer to the question: "What is this person able to do and to be?" (Nussbaum, 20II, p. 20) Capabilities represent the practically possible opportunities that the person has to realize valuable doings and beings in her daily life. A person's capability is made up by the combined interaction of internal and external factors. These include a person's internal endowments such as biology, knowledge and skills as well as the external environment including social, material and environmental factors. For example, a capability to regulate one's fertility is determined by a person's biological endowments, knowledge and skills to learn about and access fertility regulation technologies as well as external availability of such technologies, social and physical conditions that allow access to such technologies. Indeed, a person's reproductive capability can encompass a variety of pathways or opportunities to achieve fertility regulation. 
Importantly, the simple availability of contraceptive technologies in the market or the clinic without the individual physically or financially being able to access safe and effective contraceptive technologies would mean that they do not have the capability. This is a vitally important difference between a simple or formal opportunity versus the capability concept. In turn, a capability set is the "basket" of capabilities among which the individual can choose to realize outcomes. Some frequently used examples of capabilities include being able to live a long and healthy life, being able to become educated or well-nourished; being able to participate in valued productive activities; not feeling ashamed in public and interacting as an equal social member; and being able to express one's political preferences (Nussbaum, 2000, $20 \mathrm{II})^{\text {iv }}$. All these capabilities are seen to be valuable dimensions of a good life.

The second element is the notion of functionings. These are the realizations of capabilities into end achievements - the valued "beings and doings" - that an individual has chosen to pursue. The functionings correlated with the capabilities examples mentioned above would be living a long life without impairments, becoming educated; becoming well-nourished; participating in valued productive activities; not feeling ashamed in public, and expressing one's political preferences such as actually voting. Therefore, while capabilities represent the real opportunity/freedom aspect (being free and able to be or to do something), functionings refer to achieved beings or doings. Of course, while there is a need to conceptually distinguish capabilities from functionings, it should be quite clear that they are inter-related and reinforcing. Capabilities lead to functionings which in turn may create more capabilities and functionings.

An important question that arises is which capabilities and functionings are valuable? On the one hand, the CA has a strong line of ethical argument about individuals being able to choose to realize the capabilities and functionings that they personally have reason to value. On the other hand, the concept of capabilities is not meant to be a superficial concept describing people's daily mundane beings and doings (e.g. being able to use a particular kind of soap). The concept of a capability is related to human wellbeing and hence, related to concepts such as equality and social justice. Capabilities that constitute wellbeing have to be morally significant and identified through a rigorous process of reasoning. Sen argues that there should not be one standard list of capabilities identified for all societies. Instead, each society must endeavor through public reasoning to identify the basic capabilities it wants to guarantee all its members. However, when pressed for some indication of important capabilities, he does identify some basic capabilities that all societies might share in common (Sen, 2004). Martha Nussbaum, a philosopher who developed the CA together with Sen for a number of years, has identified ten human capabilities as basic or central to a minimum conception of wellbeing commensurate with equal human dignity, and which should be guaranteed to all human beings wherever we find them. Many of her ten central human capabilities are similar to the basic rights of citizens enumerated in the constitutions of countries (Nussbaum, 20l I).

Given the moral or normative aspects of capabilities and functionings they have certain characteristics: they are plural since people value multiple beings and doings, and a good life contains many things not just one; they are qualitatively distinct and, therefore, cannot be conflated or reduced to a single index or metric (such as income!) without generating distortion; they are shaped by values and reasons. That is, capabilities are identified through public and individual reasoning about a minimally decent human life in the modern world rather than reflecting facts of human biology or nature. Finally, although both capabilities and functionings are core concepts in the CA, the primary evaluative space is that of capabilities. This is because the CA considers the freedom of an individual to conceive, plan and pursue their own conception of a good life and the 
process through which outcomes are achieved to be of analytical, ethical, and political importance. Take, for example, two individuals who are severely malnourished. If we focus only on achievements, both individuals would be evaluated as being in crisis. However, if we retrospectively look at the capability space of the individuals we may find that one individual had the opportunity to be well nourished but purposefully chose to fast for religious reasons while the other person simply had no access to food. The capability space reveals the situations to be two starkly different kinds of quality of life. Analytically and morally, the capability space is the correct place to look; we care about addressing malnutrition and we also want to protect religious freedom. Alternatively, if we find that two individuals who are well nourished, but one has been forcibly fed against her will, the capability and process aspects distinguish the two situations. Outcomes are important but they do not reveal all the relevant information or accurately reflect our value of human freedom and fair process.

A third key concept is agency. Sen defines agency as the ability to pursue goals that one values and has reason to value. An agent is "someone who acts and brings about change, and whose achievements can be judged in terms of her own values and objectives, whether or not we assess them in terms of some external criteria as well" (Sen, 1999, p. (9) $)^{v}$. Agency enables people to expand their freedoms and "[freedom] is also a principal determinant of individual initiative and social effectiveness." (Sen, 1999, p.18). Thus freedoms and agency are mutually enhancing components of development: greater freedom enhances the ability of people to be agents, while agency also enables people to demand and achieve further freedoms allowing them to contribute both to their own development and to that of their community.

The fourth constitutive element is the idea of individual endowments, the amount (and quality) of resources ('things') available to the individuals. They include biological and mental features, private means (income, wealth, physical assets), public goods and services which are all instrumental to creating capabilities. An expansive definition of endowments can also include intangible resources such as political practices and social institutions, cultural practices, social norms and values, traditions and habits.

The last key element of the CA is the notion of conversion factors. One of the important and ethically relevant aspects about human beings is their diversity - in terms of biology at a point in time or across the life course as well as how each is differently situated socially, physically, culturally, relationally, and so forth. Conversion factors reflect people's different personal, social and environmental characteristics which affect either in a positive or a negative sense - their ability to effectively access and convert their endowments and external conditions into effective capabilities. These conversion factors are of fundamental importance in the CA because understanding equality as treating people equally by giving everyone the same amount of some 'thing' would result in inequality in what we most care about - equal things plus different conversion factors create inequalities in the freedoms to be and do things. Take the example of two girls who possess the same set of endowments (e.g. live same distance from a school). However, they may have very different capability sets regarding education because of their different abilities to transform their endowments due to different cultural conversation factors affecting their ability to move freely outside of their home ${ }^{\mathrm{vi}}$. By recognizing the contextual diversity of each human being in terms of their conversion factors, we are better able to create equality in the space that we really care about, the abilities of individuals to achieve valuable beings and doings that make up a good life.

The relationship between the five constitutive elements of the capability approach--capabilities, functionings, agency, endowments and conversion factors--can be represented in Figure I. 
Figure I - The constitutive elements of the capability approach

\begin{tabular}{|c|c|c|c|c|}
\hline & & & \multirow[t]{2}{*}{ Capability Set } & \multirow[t]{2}{*}{ Functionings } \\
\hline Endowments & + & $\begin{array}{l}\text { Conversion } \\
\text { factors }\end{array}$ & & \\
\hline $\begin{array}{l}\text { Biology, } \\
\text { Resources, } \\
\text { Knowledge, } \\
\text { Skills, etc. }\end{array}$ & + & $\begin{array}{l}\text { Personal, social, } \\
\text { environmental, } \\
\text { relational, } \\
\text { familial }\end{array}$ & $\begin{array}{c}\text { Effective } \\
\text { opportunities } \\
\text { (C1, C2...Cn) }\end{array}$ & $\begin{array}{l}\text { Achieved } \\
\text { outcomes }\end{array}$ \\
\hline \multicolumn{5}{|c|}{ Agency } \\
\hline
\end{tabular}

\section{How to operationalize the CA in empirical analysis}

The operationalization of a broad and complex framework such as the CA cannot aim to have a single, pure and precise quantification or a uniquely defined metric, formula and methodology to be used for many different types, purposes and contexts of investigations. Operationalizing an analytically and ethically rich theory entails being able to apply the framework in an informed manner: we should move from the abstract concepts to defining them with enough detail in order to relate them to the practical situation at hand. And, in each case be able to analyse, describe and measure relevant elements and then shape, monitor and assess responses in a normative, adequate and coherent manner.

The CA, with its multi-dimensional focus on valuable dimensions of human well-being and the ultimate aim of enhancing opportunity and process freedoms allows us to derive a more comprehensive picture of situations and thus structure more appropriate, effectively responsive and empowering policies. However, it also poses several methodological challenges.
First, it requires us to take into account a plurality of spaces: capabilities, achieved functionings, agency, process--participation and empowerment, autonomy and choice. These, amongst others, are part of the multiplicity of aspects inherent to the CA which we should consider and/or may choose to specifically focus on.

Second, it asks to identify the domains of investigation: valuable capabilities and functionings, while being context-specific, will still in all contexts encompass a vast array of domains that have to be considered such as health, education, housing, employment, participation and so forth. This may not be an issue if research is focused on one dimension of wellbeing but becomes a very prominent issue if assessing overall wellbeing of a population.

Third, once the domains of investigation have been selected, if certain domains do not have direct information there will be a need to identify variables and indicators that can be used as a proxy. These can be qualitative and/or quantitative, objective and/or subjective; they 
can be considered one by one or aggregated in a single number or index.

Fourth, it requires us to identify the primary unit of analysis: while the CA places prime focus on individuals we may be concentrating on a variety of units of analysis ranging from the individual, to the household/family, to specific population sub-groups--i.e. women, children, the elderly, different castes, ethnicities or religious groups--to considering the whole community - whether local, regional or national.

Fifth, a selection among the plurality of internal and external conversion factors that affect the conversion process of resources into capabilities and functionings will also be needed. While the abstract categories of conversion factors can act as a guide-- physical, social, environment, relational, and familial-the specific factors in a particular location must be identified.

Finally, attention needs to be paid to the relationships and linkages among the above mentioned spaces, domains and elements of analysis with regards to the specific context and study under investigation.

It is beyond the scope of this paper to offer a highly detailed and "ready-to-go" procedure on how to conduct an empirical investigation into demographic issues based on or inspired by the CA. However, we outline below the main critical steps that need to be considered and how some of the most productive empirical literature on the CA has dealt with them ${ }^{\text {vii }}$.

\section{Step 1: the data}

One of the first choices researchers have to make is identify which data are needed and/or available. The most common option is to adapt research questions to secondary data sets already available even if originally collected for other purposes. An alternative option is to gather ad-hoc information in order to create a new dataset tailored to our specific aims. The $\mathrm{CA}$ has been always considered rather demanding in terms of data requirements, and specific information on complex concepts such as capabilities, functionings or agency are hardly ever included in standard, large-scale and representative households or individuals surveys. Therefore, the need to collect primary data seems to be a forced option, particularly if we want to know about opportunities, what people are able to do or to be, even though information on outcome achievements (beings and doings) are more easily available. Looking at the CA empirical literature we find that available datasets both macro-aggregated indicators (such as UN, OECD or EU indicators) or individual level secondary data are more frequently used for measuring functionings, and less frequently for estimating capabilities as latent variables.

The category of macro data includes population censuses and large, continuous, regular and official surveys and datasets derived from administrative records. In either case, the data is generally available in aggregate format within published reports that describe the methods used and summarize the main results. National censuses and UN statistics are a typical example. Statistics are often also provided at different levels of disaggregation such as by topic, sub-population groups, geographic areas of focus or categories. Aggregate analysis can hide important underlying information as well as deep inequalities and internal disparities among subgroups of populations and individuals. This is one of the reasons, for instance, the Human Development Index in recent years has been accompanied by other measures (in particular, the Inequality Adjusted Human Development Index - IHDI - and the Multidimensional Poverty Index - MPI) based on micro-data in order to capture such inequalities. Nevertheless, even if reports generally offer figures disaggregated by individual characteristics and by socio-economic or geographical features, these levels of disaggregation are not necessarily suitable or complete enough for the purposes of a researcher's analysis. Also, conversion factors which are key components of the CA and fundamental determinants of outcomes--that 
policy makers should be made well aware of-often remain hidden within the aggregate data. Therefore, there is a need to go beyond the averages and to consider deeper the individual conditions and contexts.

Micro data is the actual raw data that contains the answers provided by each individual respondents (whether individuals and/or households) to specific inquiries. The broad spectrum of micro datasets includes, amongst others: multipurpose surveys - which usually collect both quantitative and qualitative data on a wide range of topics of broad interest; longitudinal studies - which provide information for the same respondents (individuals or households) along time and are generally used for dynamic analyses; ad hoc surveys characterized by a specific focus, for instance, on the labour force, on education, on elderly or young people, on income or wealth.

Micro-datasets gathered through sample surveys are generally more informative and allow for more refined analysis compared to aggregate data or indicators. One can choose the disaggregated level of analysis that one needs, compatible with the breadth and depth of the data collected. It provides opportunity to apply innovative, specific and possibly more adequate statistical analysis methodologies in coherence with the particular normative framework chosen and one's research questions. Households and individual level surveys usually provide a large spectrum of information that can be used and in fact have been used for measuring functionings controlling by a set of conversion factors ${ }^{\text {viii }}$. As it is shown in Nadia von Jacobi's contribution to the present special issue, Demographic Health Surveys (DHS), which are frequently used in demographic studies, represents a good example on how to make use of this datasource in order to assess achievements in important spheres of women's well-being. In addition, DHS data as well as other commonly used household surveys (e.g. EU-SILC in Europe or World Bank's LSMS), provide several data points about preferences, choices and decisions that can be used as a proxy for measuring capabilities.

More ad-hoc and accurate evidence about the set of opportunities people have can be collected through primary data, most often by qualitative analyses conducted by interviews, focus groups and participatory methods. These are used for gathering information related to values and freedom of choice, agency and empowerment as well as for assessing capabilities $^{\mathrm{ix}}$.

\section{Step 2: the variable mapping/matrix}

Once the adequate dataset has been selected it might be helpful to set up a variable matrix which contains all the variables that are relevant for one's study structured and arranged in a manner that is determined by, and coherent with, the grounding framework (Table I). The relevant variables can be classified as (proxy of) the key elements, or at least those which are most relevant for the analysis: capabilities, functionings, agency, endowments and conversion factors. The matrix should also clearly identify the levels of analysis to consider: the individual, household or the overall context.

\section{Table I. An example of a variable matrix}

\begin{tabular}{|l|l|l|l|l|l|}
\hline & Endowments & Conversion factors & Capabilities & Functionings & Agency \\
\hline Individual & & & & & \\
\hline Household & & & & & \\
\hline Context & & & & & \\
\hline
\end{tabular}


A possible path, among others, that can be followed for filling in a variable matrix can be as follows:

I. Identify an "ideal" list of aspects to include in the study.

2. Go through the questionnaire or the variable list in your dataset.

3. Verify which variables are good proxies for the elements included in the ideal list and which variables combined could give an indicator that could proxy other elements included in the ideal list.

4. Carry out a statistical analysis of the relevant variables in order to check for correlation, missing values, concentration of the sample (skewness).

5. The variables (or the created indicators) that, after the statistical test, result appropriate can create your "practical list of variables".

6. Include the "practical list of variables" in the variable matrix categorizing the various elements according to the table's headings and guided by/in coherence with the grounding theoretical framework - the capability approach.

Several issues should be considered in applying this grid. First, specific information may be interpreted differently in different empirical analysis: the same variable may be considered an endowment, or a conversion factor, or as a proxy for a capability or a functioning depending on the specific case. For instance, personal income is primarily considered as a means and therefore it will be labelled in our matrix as an endowment. However, in many cases it is also used as a proxy for determining the socioeconomic status of the household, thereby becoming a conversion factor. Similarly, education can be considered as an individual resource (e.g. endowment) to be used on the labour market for finding a job but in the capability literature is also frequently considered as a valued end and thereby, included in the list of capabilities and/or functionings. Moreover, education also plays a role as individual conversion factor that allows one to transform a certain endowment into a valued capability i.e. allowing one to make adequate use of health facilities and thereby being able to be healthy. Similarly, a women's husband's birth order if she is living in her marital household can be seen as an endowment or function as a conversion factor. Therefore, a careful interpretation of the available information is required in order to identify the potential and best use of this information for the specific issue under investigation.

Second, the data available may require using complementary data coming from other datasources in order to cover other aspects that are relevant but missing. For instance, we might need to integrate micro data with meso or macro variables related to the socio-economic context, such as the employment or unemployment rates at sub-national level, a proxy for social capital or index of corruption or governance at community level.

\section{Step 3: the empirical strategy}

A wide range of methodological tools and statistical techniques have been used in the empirical literature based on or inspired by the CA. It would be impossible to review or even list the large variety of techniques adopted for making use of the CA for empirical purposes. Roughly speaking, two main directions have been pursued ${ }^{\mathrm{x}}$.

The first one follows non-aggregative strategies and examines variables and dimensions one-by-one ${ }^{x i}$. Standard statistical methods traditionally used in the social sciences, such as regression analysis and multivariate data reduction techniques, are applied in order to select dimensions and aggregate variables, to analyse the interrelations among dimensions, to investigate the role of contextual variables or socio-demographic characteristics. Most of the empirical applications that make use of large representative household surveys adapt and combine these techniques for dealing with the challenging methodological requirements of the $C^{x i i}$. Non-aggregative strategies are relatively 
simple and make use of well-known and consolidated methods and allow for in-depth analysis and understanding of the phenomena under examination and its causes. One disadvantage associated to this strategy is the lack of synthesis and the difficulty of drawing a well-defined, possibly comparable, unitary picture.

The alternative option is to pursue a fully aggregative strategy with the construction of multidimensional indexes that are typically used for countries and/or regional ranking comparisons. The most famous example is the Human Development Index, calculated by the UNDP since 1990 using aggregate data at the global level, while the Alkire-Foster method (Alkire and Foster, 20II) represents the most recent attempt to formulate multidimensional poverty measure. An obvious advantage of this method is the possibility to rank and compare the units of analysis (e.g. countries or regions), to assess and monitor their performances in a relatively easy manner, to catch "the public's eye" (Streeten 1994, p. 235) and to raise public awareness and public debate on poverty and development issues. There are, however, some serious limitations related to the choice of indicators, their comparability at a global level, the procedures used to standardize the data and the weighting structure chosen for their aggregation. All these steps are by and large arbitrary, and each of these methodological choices can have a significant effect on the

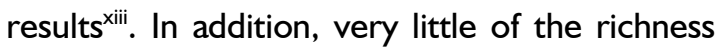
of the CA is preserved by this methodology, which is basically an attempt to go beyond unidimensional income-based measures and include some other dimensions of well-being at aggregate level.

Beside these more conventional techniques, a large range of non-standard methods of analysis, such as fuzzy methodologies (Chiappero-Martinetti 2000, 2006; BaliamouneLutz and McGillivray, 2006; Berenger and Verdier-Chouchane, 2007; Lelli, 200I; Roche, 2008; Vero, 2006), partial ranking (Brandolini and D'Alessio, 2009) and supervaluationist approaches (Qizilbash, 2002; Qizilbash and Clark, 2005) have been adopted with the aim of preserving the richness of the CA and of handling its complexity and vagueness. These methods, while innovative and promising, are not traditionally part of the "tool box" of social scientists, and require some analytical and methodological effort. Moreover, further work needs to be done on testing and consolidating these methodologies in the capabilities field.

Finally, qualitative analysis, participatory methods, focus groups and ethnographic research are now extensively used by capability scholars, particularly in fieldwork conducted in developing countries. These studies aim to investigate what "people have reason to value", to develop and agree on capability lists through deliberative consultations, to investigate the role of social and cultural norms in shaping preferences and choices, and to evaluate how participatory methods themselves can impact on people's capabilities.

There are some undeniable merits in this kind of analysis, which seems to fit well with some distinctive principles of the CA. First and foremost, people matter and it is essential to allow them to express their opinions, values and priorities. There are also evidently some limits since such methods are expensive and timeconsuming, their validity and reliability is generally difficult to verify, information on the full contexts of people's situations is not usually possible to gather in their entirety, researchers may misinterpret what people mean, and the transferability of their findings may be limited.

Overall, the growing body of empirical literature and the variety of techniques briefly outlined above should assuage concerns that the $\mathrm{CA}$ is too difficult to operationalize. While the central normative aspects of the approach are well established, more research work still needs to be done on consolidating methodological tools and experimenting with new techniques and approaches in measuring capabilities, functionings, agency, and other key components of the CA. 


\section{Common ground: Capability Approach and Population issues}

The CA offers a new perspective for understanding and measuring human wellbeing and poverty, and for designing public policies and development programs. The core principles of CA outline how human centered development should focus on people's daily life and well-being; that policies should be responsive to and enable a plurality of human activities and values, and promote and protect people's agency. The CA also asserts that social development and social change should be mainly assessed in terms of the real freedoms people have to live the life they have reason to value. Importantly, the CA also has a central hypothesis that the ends and means of development are capabilities; protecting, expanding and restoring capabilities begets more capabilities as well as achieves the standard development outcomes such as rising incomes, lower morbidity and mortality, increasing literacy, and so forth. This approach enlarges and enriches in a remarkable manner the mainstream economic concept of development as simply increasing Gross Domestic Product and other related aggregate economic indicators.

\section{Cairo ICPD and the Capability Approach}

Demographic analyses and development policies and planning have long been intertwined. One of the most important transformations in this area has been the paradigm shift from the focus on demographic targets at the population level to improving the reproductive and sexual health of individuals, especially of girls and women. In essence, it could be seen to be a shift away from aggregate indicators and functionings to a focus on capabilities. The Cairo ICPD Programme of Action' (POA) states, 'Reproductive health therefore implies that people are able to have a satisfying and safe sex life and that they have the capability to reproduce and the freedom to decide if, when and how often to do so.'(Cairo
ICPD Programme of Action para 7.2). As should be clear, there is a clear shift away from fertility control targets as promulgated by various demographic analyses toward ensuring the capability to reproduce as well as freedom and agency regarding sexual and reproductive behavior. The capability for sexual and reproductive health was fleshed out in a very detailed manner in various sections of the POA but not only dealing with reproductive health but also to do quality of life of different age and population groups such as the elderly (Article 6.19). But in line with the CA, the Cairo Consensus represented an agreement among nations (and scholars) that human beings have a moral/human right to reproductive health understood as the capability to reproduce partly constituted by the freedom to choose if, when and how to do so.

Another important shared concern between the CA and the Cairo POA is that of equity. Aside from the critique of aggregate economic indicators as being a poor reflection of the quality of life of individuals are the concerns about persistent inequalities in quality of life of individuals are obfuscated by aggregate indicators as well as the importance of fair process. The grounding of capabilities and the Cairo POA in the idea of moral claims, rights, or human rights, compels the measurement and responding to the unequal distribution of wellbeing. This concern for equity in terms of distribution of wellbeing militates against analyses and policies which seek to maximize various outcomes or achieve targets while tolerating or neglecting the deprivations of individuals who are too difficult or expensive to reach. At the same time, equity can also relate to fairness and process. While it may be true that many individuals would freely choose to control their fertility, an environment which coercively makes them control their fertility violates the principles of fairness and nondomination. Indeed, the CA asserts that equity is a complex concept and cannot be understood as a simple rule such as equal treatment. Achieving capability equity, including 
reproductive capability, requires an evaluation of multiple dimensions of capabilities including the causes, levels, distribution, consequences, agency, process, and so forth.

\section{Conclusions}

Demographic analysis and population studies traditionally deal with a plurality of interrelated aspects of human well-being (i.e. education, socio-economic status, health and reproductive health) and to manifold relevant individuals characteristics (i.e. age, gender, ethnicity) for describing and understanding population trends and demographic phenomena. In this paper we described how the ethically rich, conceptually complex and multi-layered structure offered by the capability approach can be particularly suitable for conceptualizing and contextualizing demographic issues from a broader and more comprehensive perspective. As the case studies discussed in this special issues show investigating within a robust and broad theoretical framework the linkages among the plurality of circumstance at the individual, household and contextual level, and how they can affect and determine, for instance, reproductive health choices and decisions, can offer new interesting insights for demographic analysis.

In drawing on the CA, it must be recognized that several conceptual and methodological issues are still unsettled and evolving in the capability literature. These include, among others, aspects such us how to select and define a list of valuable capabilities for individual wellbeing, the demanding need of statistical data, and the lack of a unique formula or algorithm for operationalizing this framework. However, the extensive and growing body of empirical applications of the CA, in a broad range of fields of investigation, show that researchers can meet most of the challenges posed by this approach by adopting various empirical strategies and technical solutions. We would argue that it would be worthwhile for demographers to draw on the existing $C A$ empirical evidence and researcher experiences and integrate it with the prevailing demographic analysis in order to move towards a new frontier and possibly open up new areas of inquiry.

\section{References}

Alkire, S. (2002). Valuing freedoms: Sen's capability approach and poverty reduction. Oxford New York: Oxford University Press.

Alkire, S. and Deneulin S. (2009). The human development and capability approach, in Deneulin, Séverine; Shahani, Lila, An introduction to the human development and capability approach freedom and agency, Sterling, Va. Ottawa, Ont: Earthscan International Development Research Centre, 22-48.

Alkire, S. and Foster J. (20II). Counting and multidimensional poverty measurement, Journal of Public Economics, 95(7-8), 476487.

Anand, P.. Hunter, G. and R. Smith (2005). Capabilities and Well-Being: Evidence Based on the Sen-Nussbaum Approach to Welfare, Social Indicators Research, 74 (I), 9-55.

Anand, P., Krishnakumar, J. and Tran, N.B. (20II). Measuring welfare: Latent variable models for happiness and capabilities in the presence of unobservable heterogeneity, Journal of Public Economics, 95(3-4), 205215.

Anand, P., Hunter G., Carter I., Dowding K., and van Hees M. (2009). The Development of Capability Indicators, Journal of Human Development and Capabilities, Taylor and Francis Journals, 10 (I), I25-152.

Baliamoune-Lutz, M. and McGillivray, M. (2006). Fuzzy Well-being achievement in Pacific Asia, Journal of the Asia Pacific Economy, II, 168-177.

Berenger, V. and Verdier-Chouchane, A. (2007). Multidimensional measures of wellbeing: standard of living and quality of life across countries, World Development. 35 (7), 1259-1276. 
Brandolini, A. and D'Alessio G. (2009). Measuring well-being in the functioning space in Chiappero-Martinetti E., Roche J.M. (2009), 9I-I56.

Chiappero-Martinetti, E. (2000). A multidimensional assessment of well-being based on Sen's functioning approach, Rivista Internazionale di Scienze Sociali, CVIII, 2, 207-239.

Chiappero-Martinetti, E. (2006). Capability Approach and Fuzzy Set Theory: Description, Aggregation and Inference Issues, in A. Lemmi and G. Betti (eds.) Fuzzy Set Approach to Multidimensional Poverty Measurement. New York: Springer.

Chiappero-Martinetti, E. and Roche, J.M. (eds), (2009). Operationalization of the Capability Approach" in Enrica Chiappero-Martinetti. Debating Global Society: Reach and Limits of the Capability Approach, Milano: Fondazione Giangiacomo Feltrinelli.

Chiappero-Martinetti, E. and von Jacobi N. (20/2), Light and shade of multidimensional indexes: how methodological choices impact on empirical results, in Quality of life in Italy: research and reflections, Maggino $F$. and Nuvolati G. (eds), Springer, 69-106.

Chiappero-Martinetti, E., Egdell V., Hollywood E. and McQuaid R. (2014) Operationalisation of the Capability Approach (forthcoming in a collected volume published by Springer).

International Conference on Population and Development- ICPD- Programme of Action. 5-13 September 1994

https://www.unfpa.org/public/global/publicat ions/pid/I 973.

Klasen, S. (2000). Measuring poverty and deprivation in South Africa, Review of Income and Wealth. 46, 33-58.

Kuklys, W. (2005). Amartya Sen's Capability Approach: Theoretical Insights and Empirical Applications. Berlin : Springer Verlag.

Lelli, S. (200I). Factor Analysis vs. Fuzzy Sets Theory: Assessing the Influence of Different Techniques on Sen's Functioning Approach, Centre of Economic Studies Discussion Paper, KU Leuven.
Nussbaum, M. (2000). Women and Human Development: the Capabilities Approach. Cambridge: Cambridge University Press.

Nussbaum, M. (201 I). Creating capabilities. The human development approach. Harvard, Harvard University Press.

Qizilbash, M. (2002). A note on the measurement of poverty and vulnerability in the South African context, Journal of International Development, 14, pp. 757-772.

Qizilbash, M. and Clark, D. (2005). The Capability Approach and Fuzzy Poverty Measures: An application to the South African Context, Social Indicators Research, 74, 103-129.

Ravaillon, M. (20I0a). The mushup indices of development, Policy Research Working Paper, no. 5432, World Bank, Washington DC.

Ravaillon, M. (20I0b). Troubling tradeoffs in the Human development Index, Policy Research Working Paper 5434, World Bank, Washington DC.

Ravaillon, M. (20II). On multidimensional indices of poverty, Policy Research Working Paper, n. 5580, World Bank, Washington DC.

Robeyns, I. (2005). The capability approach: a theoretical survey, Journal of Human Development, 6 (I), 93-II 7.

Robeyns, I. (2006). The capability approach in practice, Journal of Political Philosophy, 14, 35I-376.

Roche, J.M. (2008). Monitoring Inequality among Social Groups: A Methodology Combining Fuzzy Set Theory and Principal Component Analysis, Journal of Human Development, 9 (3), 427-452.

Sen, A. (1985). Commodities and capabilities. Amsterdam: Elsevier.

Sen A. (1992). Inequality re-examined Oxford, Oxford University Press.

Sen, A. (1999). Development as Freedom. New York: Knopf Press. 
Sen, A. (2004). Capabilities, Lists, and Public Reason: Continuing the Conversation. Feminist Economics, 10, 77-80.

Sen, A. (2009). The Idea of Justice. London : Allen Lane.

Streeten, P. (1994). Human Development: Means and Ends, American Economic Review. 84 (2), 232-237.

Vero, J. (2006). A comparison of poverty according to primary goods, capabilities and outcomes. Evidence from French School Leavers' Survey, in Lemmi, A. and Betti, G. (eds) Fuzzy Set Approach to Multidimensional Poverty Measurement. New York: Springer.

\begin{abstract}
' This paper is partially based on a broader toolkit on the capability approach under preparation. The author thanks Lia Quartapelle and Alberta Spreafico for their contribution to earlier version of the toolkit. Both authors also thank Claudine Sauvain-Dugerdil for the appreciated suggestions offered.
\end{abstract}

ii The capabilities approach also provided the theoretical foundation for the Human Development Reports that have been annually issued since 1990 by the United Nations Development Program (UNDP) and the popular Human Development Index (see www.

http://hdr.undp.org).

iii For a theoretical introduction to the CA see also Robeyns (2005, 2006).

iv Nussbaum (2011) distinguishes further three different notions of capabilities, namely basic, internal and combined capabilities.

$\checkmark$ The opposite of a person with agency is someone who is forced, oppressed or passive (Alkire, 2002; Alkire and Deneulin, 2009).

vi Examples of personal conversion factors are age, ethnicity, gender, physical condition and presence of disabilities. Social conversion factors usually refer to family socio-economic background and characteristics of the social contexts where people live. Environmental conversion factors are mostly connected to the natural environment, the climate conditions etc.

vii For a more detailed presentation on different empirical strategies used for operationalizing the CA see Chiappero Martinetti and Roche (2009) and also Chiappero-Martinetti et al (2014).

viii See, amongst others, Chiappero-Martinetti (2000), Klasen (2000), Lelli (2001), Kuklys (2005), Roche (2008).

ix Anand et al. (2005, 2009, 2011).

${ }^{x} \mathrm{~A}$ more extensive presentation of these methods is discussed in Chiappero and Roche (2009) and Chiappero et al. (2014).

xi Is what Brandolini and D'Alessio (2009) define a "supplementation strategy", which typically entails using monetary indicators in conjunction with nonmonetary ones, which may refer to specific capabilities or functionings. In most cases is just an extension of more standard uni-dimensional poverty or inequality analysis in a multidimensional space. Sometimes comparison is done on the basis of the entire vector of capabilities or functionings under consideration (instead of item-by-item).

xii Even if much progress has been made in operationalisation, some distinctive features of this approach, such as the distinction between opportunities and achievements, the freedom of choice, the agency aspects are difficult to capture with these techniques.

xiii Ravaillon (2010a) outlines that most of the "mashup indices" of development and poverty currently available are rarely rooted into a prevailing theory or grounded on robust methodological assumptions. For a discussion on this issue see also Ravaillon (2010b, 2011) and the contributions to the special issue of the Journal of Economic Inequalities, vol. 9, no.2,2011. See also Chiappero-Martinetti and von Jacobi (2012). 